\title{
Is Shortwave Diathermy Effective on Mortality of Protoscolices?
}

\author{
Zahra Eslamirad $^{1}$, Reza Hajihossein ${ }^{1}$, Homa Soleimani ${ }^{2 *}$ \\ ${ }^{1}$ Department of Medical Parasitology and Mycology, School of Medicine, Arak University of Medical Sciences, Arak, Iran; \\ ${ }^{2}$ Department of Medical Physics and Physiology, School of Medicine, Arak University of Medical Sciences, Arak, Iran
}

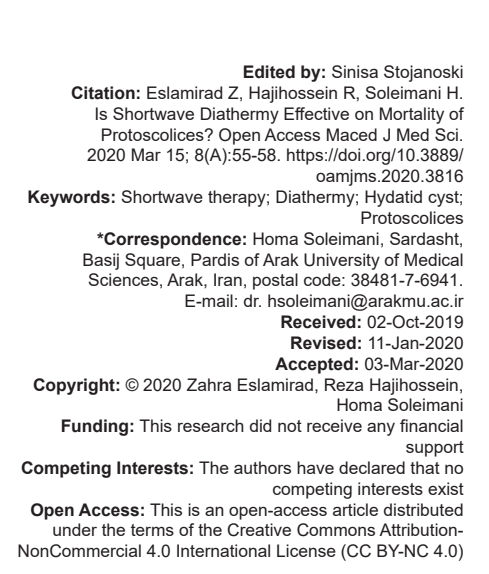

\section{Abstract}

AIM: A previous study confirmed the effect of microwaves on protoscolices in vitro. In the current study, the effect of shortwave diathermy (SWD) on the protoscolices of hydatid cysts was investigated.

MATERIALS AND METHODS: The hydatid cyst was collected from the slaughterhouse and its contents were drained sterilized. SWD therapy was done in continuous mode. The experiment was conducted based on electrode area, power of device, and exposure time. GraphPad and SPSS software was used for data analysis.

RESULTS: The study results showed that the two main factors of time exposure and power of the machine could significantly effective in the mortality rate of protoscolices compared to control $(p<0.0001)$. Scolicidal activity of SWD in $450 \mathrm{w}$ was $4.5 \%, 8.3 \%$, and $10 \%$, respectively, after 2,5 , and 10 min with $\Delta \mathrm{T}=0.5^{\circ} \mathrm{C}, 14^{\circ} \mathrm{C}$, and $16^{\circ} \mathrm{C}$. The results of the study showed that the simultaneous effect of two factors of power and time exposure increased significantly death rate of protoscolices compared to control $(p<0.05)$.

CONCLUSION: Since the application of SWD has limited risks, ease of use, and relative low cost and it can induce hyperthermia in depth of tissues, continuous SWD can be used as a tool for preoperative in surgery. However, it is likely that scolicidal activity can be observed by changing the device mode in pulse short wave at a lower temperature and also the possible side effects need further investigation in vivo.

\section{Introduction}

Hydatidosis or cystic echinococcosis (CE) is a chronic disease caused by the larval stage of Echinococcus spp. tapeworm [1].

The World Health Organization (WHO) considers the CE to be a neglected tropical disease because it not only causes a dangerous disease in humans but also lead to high medical and economic costs [2], [3]. The gold standard therapeutic methods for CE are surgical treatment. This is an invasive procedure and the risks; complications and costs are high [4]. In recent years, research has been conducted to find non-invasive treatment for the disease. Many researchers are trying to find effective and low-risk therapeutic procedures for the disease such as the use of radiofrequency electromagnetic waves, in vitro, and in vivo [5], [6].

Shortwave radio frequencies are a type of electromagnetic radiation which often referred to forms of high-frequency electromagnetic radiation, which are classified as non-ionizing radiation $\left(0.1-10^{13} \mathrm{~Hz}\right)$ with a wavelength of between 10 and $100 \mathrm{~m}$ [7].

A considerable period of time physiotherapists has utilized shortwave diathermy (SWD) in continuous and pulsed mode to cause thermal and non-thermal effects on tissues. The most appropriate term for the waves used in this type of therapy would be $11 \mathrm{~m}$. The frequency of oscillations of these waves corresponds to $27.12 \times 10^{6} \mathrm{~Hz}$ [8]. Continuous SWD was reported as an effective treatment for acute and chronic soft tissue. The machine for producing these waves induces oscillating electrical fields which produce magnetic fields. SWD machine is a signal generator that uses either inductive or capacitive electrodes to deliver energy to the body which led to considerable physiological effects in tissue [9]. Hence, SWD can change physiological processing consist of increasing blood flow, relieving joint stiffness, pain and inflammation, decreasing hematoma and edema, reduction in muscle spasm, increasing soft tissue elasticity, and acceleration in speeding the recovery of wounds [10], [11].

This kind of treatment is non-invasive and its application has limited risks, ease of use, and relative low-cost. It can be applied locally to the target tissue and can induce a significant deep-heating response in human soft tissues through and, most importantly, it proved efficacy in many clinical areas [10]. These features have caused; it has become very popular with clinical therapists. It is likely the clinical application of shortwave (radio-frequency) diathermy to become increasingly widespread in the next years. However, research of its effects and clinical efficacy are scarcity conspicuous. 
To use this particular modality, it seems to require more practical scientific evidence for its efficacy. In the current in vitro study, the effect of SWD on the protoscolices of hydatid cysts based on two variables of the power and time exposure of radiation was investigated.

\section{Materials and Methods}

This experimental study was done on protoscolices obtained from the hydatid cyst.

\section{Preparation of protoscolices and viability test}

Sheep hydatid cysts were collected from abattoir of Arak city in Markazi Province and transferred to Parasitology Laboratory in Arak University of Medical Sciences. The content of cysts was completely depleted by a sterile syringe and washed 3 times with normal saline. The concentration of protoscolices was set by normal saline and the suspension containing 9000-10,000 protoscolices/milliliter was provided. The viability of protoscolices was determined by the eosin stain method. The suspension of live protoscolices was transferred to a dark container and stored at $4^{\circ} \mathrm{C}$ for future use [12]. This suspension was aliquot into identical tubes and in equal volume.

\section{SWD treatment}

SWD irradiation was performed using SWD instrument (CURAplus 419; ENRAF-NONIUS).

To produce a uniform electric field, two same electrode surface area $\left(8.5 \mathrm{~cm}^{2}\right)$ was used. Furthermore, to produce the density of the electric field lines, two electrode with different sizes $\left(8.5 \mathrm{~cm}^{2}, 2.5 \mathrm{~cm}^{2}\right)$ was used. Samples were treated with SWD using "contra planar" technique. Hence, the electrodes were placed in parallel with samples (samples were placed in $1 \mathrm{~cm}$ from each electrode). All experiments were done in continuous mode. The experiment was conducted as follows:

A. Comparison of the mortality rate of protoscolices based on electrode area in $350 \mathrm{w}$ power. Samples were divided into two groups, including four subgroups according to time exposure $(0$, $0.5,1$, and $2 \mathrm{~min})$. The first group was exposed to SWD by the same electrodes with an area of $8.5 \mathrm{~cm}^{2}$ and the second group was treated with exposure by two non-identical electrodes (8.5 and $4.25 \mathrm{~cm}^{2}$ ).

B. Comparison of the mortality rate of protoscolices based on power of the device with two nonidentical electrodes ( 8.5 and $4.25 \mathrm{~cm}^{2}$ ) in 350 and $450 \mathrm{w}$ power. Samples were divided into two groups, including three subgroups according to time exposure $(0,5$, and $10 \mathrm{~min})$. The $1^{\text {st }}$ and $2^{\text {nd }}$ groups, respectively, were exposed to SWD in 350 and $450 \mathrm{~W}$. as follows:

The protoscolices mortality rate was calculated

Mortality rate $(\%)=$ (number of dead protoscolices in each subgroup-number of dead protoscolices before irradiation/total protoscolices) $\times 100$

The temperature change in the protoscolices suspensions was monitored before and after the irradiation with a thermocouple (Tp-01, Lutron Electronic Enterprise Co., Taiwan). The temperature of the suspension was measured with an accuracy of $0.1^{\circ} \mathrm{C}$ when the probe was inserted into the suspension. The temperature was shown as $\Delta \mathrm{T}$, representing the temperature difference in protoscolices suspension before and after the irradiation [5].

\section{Statistical analysis}

GraphPad Prism (version 6) and SPSS (version 16) software was used for data analysis. The mortality rate and $\Delta T$ were presented as mean values in three separate experiments and expressed as mean \pm $\mathrm{SD}$. Differences between the subgroups and the control were analyzed with a repeated measure test.

\section{Results}

The comparison of protoscolices mortality rate and $\Delta T$ when the radiation power was constant $(350 \mathrm{~W})$, but the area of electrodes was changed is shown in Table 1.

Table 1: Comparison of the mortality rate of protoscolices in similar power $(350 \mathrm{w})$ irradiation of SWD but different electrode area

\begin{tabular}{llllll}
\hline Exposure time (min) & \multicolumn{2}{l}{$\begin{array}{l}\text { Electrodes size identical } \\
\left(8.5 \mathrm{~cm}^{2}\right)\end{array}$} & & $\begin{array}{l}\text { Electrodes size different }(8.5 \\
\left.\text { and } 4.25 \mathrm{~cm}^{2}\right)\end{array}$ \\
\cline { 2 - 3 } & Mortality $(\%)$ & $\Delta \mathrm{T}\left({ }^{\circ} \mathrm{C}\right)$ & & Mortality $(\%)$ & $\Delta \mathrm{T}\left({ }^{\circ} \mathrm{C}\right)$ \\
\hline 0 & $0.33 \pm 0$ & 0 & & $0.33 \pm 0$ & 0 \\
0.5 & $2.5 \pm 0.7$ & $4.5 \pm 0.7$ & & $3.25 \pm 0.85$ & $4.3 \pm 0.71$ \\
1 & $3.5 \pm 0.71$ & $5.5 \pm 0.7$ & & $3.85 \pm 0.7$ & $4.5 \pm 0.7$ \\
2 & $4 \pm 1.4$ & $4.5 \pm 0.7$ & & $4.15 \pm 0.71$ & $4 \pm 1.41$ \\
\hline SWD: Shortwave diathermy. & & & & & \\
\end{tabular}

The comparison of protoscolices mortality rate and $\Delta T$ when the area of electrodes was constant but the radiation power was changed is shown in Table 2.

Table 2: Comparison of the mortality rate of protoscolices in similar electrode area (non-identical electrodes) but different power SWD

\begin{tabular}{|c|c|c|c|c|}
\hline \multirow[t]{2}{*}{ Exposure time (min) } & \multicolumn{2}{|l|}{$350 \mathrm{w}$ power } & \multicolumn{2}{|l|}{$450 \mathrm{w}$ power } \\
\hline & Mortality (\%) & $\Delta \mathrm{T}\left({ }^{\circ} \mathrm{C}\right)$ & Mortality (\%) & $\Delta \mathrm{T}\left({ }^{\circ} \mathrm{C}\right)$ \\
\hline 0 & $0.33 \pm 0$ & 0 & $0.33 \pm 0$ & 0 \\
\hline 5 & $5.5 \pm 0.57$ & $7.1 \pm 0.3$ & $8.3 \pm 1.5$ & $14 \pm 2.6$ \\
\hline 10 & $7.1 \pm 0.57$ & $12.5 \pm 0.7$ & $10.5 \pm 0.7$ & $16 \pm 2.1$ \\
\hline
\end{tabular}


The comparison of repeated measure analysis for the mortality rate of protoscolices based on exposure radiation time with the power of SWD and electrodes surface area is shown in Figure 1.

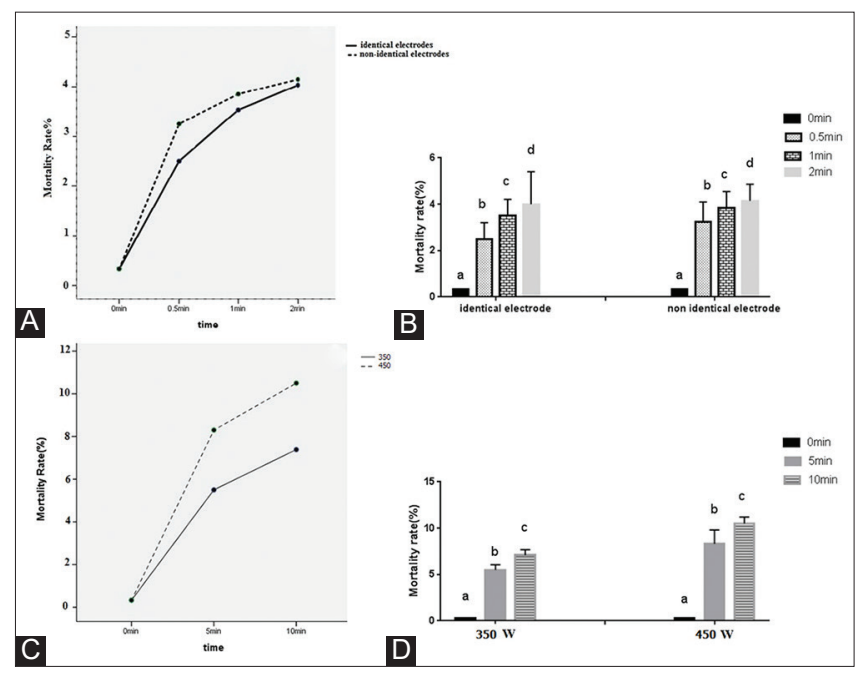

Figure 1: (A) Diagram of the repeated measure test based on exposure time and electrodes surface area; $(B)$ diagram of the repeated measure test based on exposure time and power of SWD; $(C, D)$ different letters " $a, b, c, d$ " refer to significant differences according to repeated measure test $(p<0.05)$. "a" letter means, there was a significant difference between "a" group with "b" group and "c" group and " $d$ " group, but there was not a significant difference between groups with the same letter

\section{Discussion}

Since the World Health Organization's working group on Hydatidosis proposed urgently needs to new treatment protocol which would be more effective with fewer complications, so often researchers are studying the subject [13].

The purpose of the evaluation of new therapeutic methods is to find applicable procedures with low complications that require little hospital facilities [14].

Radio frequency electromagnetic is known as non-invasive procedure has been enabled by the advance of various medical technologies [15]. The researchers showed that electromagnetic field (REF) effect on cell membrane leads to changes in transport of ions across the membrane [16].

Furthermore, the cell membrane can become more fluid [17], [18]. The permeability of the cell was changed, possibly allowing some potentially harmful molecules to enter and allow more movement of proteins and other molecules in and through the membrane [19]. Both integral and peripheral proteins in the membrane can also be damaged by high temperatures and, if extremely high, heat might cause these proteins to break down, or denature [16]. Vent Hoff's law states that a chemical reaction speed is temperature-dependent and for every $10^{\circ}\left(100^{\circ} \mathrm{C}\right)$ rise in temperature, it enhances two or three-fold. Thus, temperature increasing of tissue from the $37^{\circ} \mathrm{C}$ to $40-45^{\circ} \mathrm{C}$ will accelerate the metabolism of the cell as the rate of consumption of oxygen and expenditure energy increase 1.5 times normal [8].

Some studies indicated that hyperthermia, locally or whole body, is a method for treatment some malignant tumors. One of the effective ways of inducing hyperthermia is applied of microwave. These waves rapidly raised temperature locally in areas with a low depth [20]. However, we need an alternative method in heating deep laying tissues and heating a relatively large volume of tissue. SDW can induce hyperthermia in length deep. It can produce heating depend on electrode surface area in a large volume [8], [10].

Therapeutically, a temperature increase of more than $1^{\circ} \mathrm{C}$ causes relieving in mild inflammation and an arising temperature between 2 and $3^{\circ} \mathrm{C}$ is led to decreasing in muscle spasm and pain, changes in tissue extensibility are happening with a rising temperature $3-4^{\circ} \mathrm{C}$. If the rising temperature is lower than $1^{\circ} \mathrm{C}$, the effect of the thermal of SWD on cell behavior will reversible [21].

From 0 up $2 \mathrm{~min}$, although the change in electrode surface area has not been effective in increasing the mortality rate of protoscolices. However, the mortality rate was, respectively, $3.25 \%, 3.85$, and $4.15 \%\left(\Delta 4-4.3^{\circ} \mathrm{C}\right)$ at the end of $0.5,1$, and $2 \mathrm{~min}$. Moazeni et al. indicated a mortality rate of protoscolices by warm water at temperature $\left(\Delta 20-24^{\circ} \mathrm{C}\right)$ was 0.4 and $2.9 \%$ at 1 and 2 min in vitro.

It is likely that instead of a radiation session (1 $\mathrm{min}$ ), we use several 1-min sessions of radiation or using a pulse SWD use as alternative method, so the mortality rate would be reached to the optimum level or level which can be effective as a pre-surgery.

Our study showed that 0 up 10 min time has been an effective factor in increasing the mortality rate $(p<0.0001)$. However, another effective factor in enhancing the mortality rate of protoscolices was power of machine, and this was directly related to the temperature rise, so mortality rate was, respectively, $8.3 \%$ and $10 \%\left(\Delta 14^{\circ}\right.$ and $\left.16^{\circ} \mathrm{C}\right)$ at the end of 5 and $10 \mathrm{~min}$. Moazeni et al. indicated that the mortality rate of protoscolices by warm water at the lowest temperature $\left(\triangle 20-24^{\circ} \mathrm{C}\right)$ was 10.2 and $20.4 \%$, respectively, at 5 and $10 \mathrm{~min}$ in vitro.

It is likely that according to research conducted, using PSWD, selecting the appropriate time session and electrode surface (for localized electric density) can provide a proper effect in relatively low temperatures.

Further studies are needed to provide deeper insight in such subtle power and thermal phenomena determine any side effects in vivo that possible effect on protoscolices. 


\section{Acknowledgment}

This study is according to the results of a research project approved by the Ethics Committee of the Arak University of Medical Sciences (92-143-19). Furthermore, the authors wish to thank the deputy of research at Arak University of Medical Sciences for their support. The authors thank Mr. Sabetghadam from Red Crescent Organization (Arak) for technical assistance.

\section{References}

1. Eckert J, Deplazes P. Biological, epidemiological, and clinical aspects of echinococcosis, a zoonosis of increasing concern. Clin Microbiol Rev. 2004;17(1):107-35. https://doi.org/10.1128/ cmr.17.1.107-135.2004

PMid:14726458

2. Fasihi Harandi M, Budke CM, Rostami S. The monetary burden of cystic echinococcosis in Iran. PLoS Negl Trop Dis. 2012;6(11):e1915. https://doi.org/10.1371/journal.pntd.0001915 PMid:23209857

3. Budke CM, Deplazes P, Torgerson PR. Global socioeconomic impact of cystic echinococcosis. Emerg Infect Dis. 2006;12(2):296-303. https://doi.org/10.3201/eid1202.050499 PMid:16494758

4. Velasco-Tirado V, Alonso-Sardón M, Lopez-Bernus A, RomeroAlegría Á, Burguillo FJ, Muro A, et al. Medical treatment of cystic echinococcosis: Systematic review and meta-analysis. BMC Infect Dis. 2018;18(1):306-6.

PMid:29976137

5. Eslamirad Z, Soleimani H, Hajihossein R, Rafiei F. Evaluation of lethal effect of microwave exposure on protoscolices of hydatid cyst in vitro. Asian Pac J Trop Dis. 2015;5(10):821-4. https://doi. org/10.1016/s2222-1808(15)60938-0

6. Botsa E, Thanou I, Nikas I, Thanos L. Treatment of hepatic hydatid cyst in a 7-year-old boy using a new type of radiofrequency ablation electrode. Am J Case Rep. 2017;18:953-8. https://doi. org/10.12659/ajcr.904432

PMid:28871077

7. Putowski M, Piróg M, Podgórniak M, Padała O, Sadowska $M$, Bazylevycz A, et al. The use of electromagnetic radiation in the physiotherapy. EJMT. 2016;2(11):53-8.

8. Goats GC. Continuous short-wave (radio-frequency) diathermy. Br J Sports Med. 1989;23(2):123-7. https://doi.org/10.1136/ bjsm.23.2.123

PMid:2691003

9. Goats GC. Pulsed electromagnetic (short-wave) energy therapy. Br J Sports Med. 1989;23(4):213-6.

\section{PMid:2629997}

10. Garrett $\mathrm{CL}$, Draper DO, Knight KL. Heat distribution in the lower leg from pulsed short-wave diathermy and ultrasound treatments. J Athl Train. 2000;35(1):50-5.

\section{PMid: 16558608}

11. Cole AJ, Eagleston RA, Herring SA. The benefits of deep heat Phys Sportsmed. 1994;22(2):76-88.

PMid:27437601

12. Hajihossein R, Eslamirad Z, Mosayebi M, Ghasemikhah R, Didehdar M. In vitro effects of vinegar on protoscolices of hydatid cyst. Asian Pac J Trop Dis. 2015;5(3):210-3. https://doi. org/10.1016/s2222-1808(14)60655-1

13. Barzin Z, Sadjjadi SM, Panjehshahin MR. Protoscolicidal effects of the garlic chloroformic extract on the protoscolices of hydatid cyst at a short exposure time, up to five minutes. Iran J Med Sci. 2019;44(1):28-34.

PMid:30666073

14. Botezatu C, Mastalier B, Patrascu T. Hepatic hydatid cystdiagnose and treatment algorithm. J Med Life. 2018;11(3):203-9. PMid:30364592

15. Zimmerman JW, Jimenez $\mathrm{H}$, Pennison MJ, Brezovich I, Morgan D, Mudry A, et al. Targeted treatment of cancer with radiofrequency electromagnetic fields amplitude-modulated at tumor-specific frequencies. Chin J Cancer. 2013;32(11):573-81. https://doi.org/10.5732/cjc.013.10177

PMid:24206915

16. Lucia U, Ponzetto A, Deisboeck TS. Constructal approach to cell membranes transport: Amending the "Norton-Simon" hypothesis for cancer treatment. Sci Rep. 2016;6:19451. https:// doi.org/10.1038/srep19451

PMid:26822208

17. Monzel C, Sengupta K. Measuring shape fluctuations in biological membranes. J Phys D. 2016;49(24):243002. https:// doi.org/10.1088/0022-3727/49/24/243002

18. Hanna H, Denzi A, Liberti M, André FM, Mir LM. Electropermeabilization of inner and outer cell membranes with microsecond pulsed electric fields: Quantitative study with calcium ions. Sci Rep. 2017;7(1):13079. https://doi.org/10.1038/ s41598-017-12960-w

PMid:29026094

19. Greenebaum B, Barnes F. Bioengineering and Biophysical Aspects of Electromagnetic Fields. $4^{\text {th }}$ ed. Florida, United States: CRC Press; 2018.

20. Cairang Y, Zhang L, Ren B, Ren L, Hou L, Wang H, et al. Efficacy and safety of ultrasound-guided percutaneous microwave ablation for the treatment of hepatic alveolar echinococcosis: A preliminary study. Medicine (Baltimore). 2017;96(27):e7137. https://doi.org/10.1097/md.0000000000007137 PMid:28682866

21. Watson T. Pulsed and continuous shortwave therapy In: Al-Mandeel MM. Electrotherapy: Evidence-based Practice. $14^{\text {th }}$ ed. United Kingdom: Elsevier Health Sciences; 2014 p. $137-60$. 